\title{
ENXERTO AUTÓGENO EM BLOCO CORTICOMEDULAR EM MAXILA: RELATO DE CASO
}

\section{Pâmella Santana Nunes}

Acadêmica da Faculdade de Odontologia da Universidade Federal Fluminense - UFF Niterói/RJ.

\section{Isabelly de Vasconcellos Pereira}

Pós-graduanda do curso de especialização em Implantodontia na Universidade Federal Fluminense - UFF, Niterói/RJ.

\section{Frederico Martins da Silva}

Pós-graduando do curso de especialização em Prótese Dentária na Associação Brasileira de Odontologia - ABO/RJ, Rio de Janeiro/RJ.

\section{Rafael Seabra Louro}

Professor da disciplina de Cirurgia Oral Menor da Universidade Federal Fluminense UFF, Niterói/RJ.

\section{Rodrigo Figueiredo de Brito Resende}

Professor da disciplina de Cirurgia Oral Menor da Universidade Federal Fluminense UFF, Niterói/RJ.

Instituição na qual o trabalho foi realizado: Faculdade de Odontologia da Universidade Federal Fluminense Niterói/RJ

Categoria: Relato de caso

\section{Informações do autor principal:}

Nome: Isabelly de Vasconcellos Pereira

Endereço: Rua Mário Santos Braga, 28, Faculdade de Odontologia.

E-mail: vasconcellosisabelly@gmail.com

Telefone: (21) 96428-5736 


\title{
Resumo
}

A instalação de implantes dentários osseointegráveis em regiões previamente enxertadas foi primeiramente descrita por Brånemark em 1975, e continua tendo sua indicação nos dias atuais, com altas taxas de sucesso. Apesar do crescimento dos biomateriais xenógenos e aloplásticos, os enxertos autógenos continuam sendo reconhecidos como "padrão ouro" dentro da Medicina e Odontologia. Isso se dá devido ao fato de ser o único enxerto com características de osseoindução, osseocondução e osteogênse. Dessa forma, geralmente, consegue-se ganho ósseo em altura e/ou espessura, permitindo a correção de defeitos ósseos verticais e/ou horizontais, para realizar a posterior reabilitação do paciente com implantes. Entre os sítios intra-orais doadores possíveis, podemos citar o ramo mandibular, mento e túber. $\mathrm{O}$ mento se destaca como área doadora por oferecer quantidade e qualidade ósseas, tanto cortical como medular, além de se apresentar com um ótimo acesso cirúrgico. O objetivo desse trabalho é relatar um caso clínico da paciente A.R.L.S, leucodema, sexo feminino, 56 anos de idade, que foi atendida na Clínica de Extensão em Dentes Inclusos e Cirurgia Oral da Faculdade de Odontologia da Universidade Federal Fluminense, para realização de enxerto autógeno na região anterior de maxila, para posterior instalação de implantes para reabilitação, utilizando a região de mento como doadora.

Palavras-chave: enxerto autógeno; implante osseointegrável; enxerto em bloco.

\begin{abstract}
The installation of osseointegrated dental implants in previously grafted regions was first described by Brånemark in 1975, and continues to be indicated today, with high success rates. Despite the growth of xenogen and alloplastic biomaterials, autogenous grafts continue to be recognized as the "gold standard" within medicine and dentistry. This is due to the fact that it is the only graft with characteristics of bone induction, bone conduction and osteogenesis. Thus, generally bone gain in height or thickness is achieved, allowing the correction of vertical or horizontal bone defects, for subsequent rehabilitation of the patient with implants. Possible donor intraoral sites include the REVISTA FLUMINENSE DE ODONTOLOGIA - ANO XXVI - No 53 - Janeiro / Julho 2020
\end{abstract}


mandible branch, mental symphysis and maxillary tuberosity. The mental symphysis stands out as a donor area because it offers bone quantity and quality, both cortical and medullary, and presents with excellent surgical access. The objective of the present study is to report a clinical case of a 56-year-old female patient, ARLS, leucoderma, who was seen at the Clinic of Extension in Teeth and Oral Surgery of Fluminense Federal University Dentistry School, to perform autogenous graft in the anterior region maxillary for later implantation for rehabilitation, using the mental symphysis region as a donor.

Key-words: autogenous graft; osseointegrated implant; block graft.

\section{Introdução}

Estima-se que, após exodontias, o osso alveolar reabsorva em média $25 \%$ no primeiro ano após a extração. A causa da perda do elemento dentário está diretamente ligada e pode acelerar a reabsorção, como doença periodontal, hábitos alimentares e de higienização, trauma dentário e/ou alveolar, patologias, entre outros. (MAZZONETTO, R. ET AL, 2009). Apesar de seguir padrão diferente entre maxila e mandíbula, esse processo é progressivo e resulta num rebordo edêntulo atrófico tanto na arcada superior quanto na inferior, tornando-se um fator comumente limitante para reabilitação por implante osseointegrável (MAZZONETTO, R. ET AL, 2009; KLASSMANN, F.A., ET AL. 2006).

Para garantir previsibilidade à reabilitação, é importante que se tenha quantidade e qualidade óssea no local da instalação do implante dentário. A reconstrução óssea previamente realizada reestabelece as condições biológicas favoráveis de biomecânica para osseointegração e de estética (MEDONÇA, J.C.G. ET AL, 2015). Enxertos de osso corticomedular são uma alternativa para aumentar rebordo atrófico. A depender do defeito e do volume necessário para reconstrução, os enxertos autógenos são a alternativa mais viável, podendo-se realizar a instalação do implante após 4 a 6 meses de cicatrização (HUPP JR, ELLIS E, TUCKER MR, 2009).

Outros tipos de enxertos podem ser propostos, como o alógeno e xenógeno, contudo o enxerto autógeno é considerado "padrão ouro" devido aos mecanismos de ação 
conhecidos de osteocondução, osteoindução e osteogênese (MAZZONETTO, R. ET AL, 2009). Obtido de sítio doador do próprio indivíduo, o enxerto autógeno foi descrito em 1975, por Branemark, como uma alterativa previsível para reconstruções de defeitos ósseos bucais (MEDONÇA, JCG ET AL, 2015). Pode ser utilizado em bloco ou particulado para reconstruções alveolares, considerando o tipo de reparo planejado, o volume necessário e a biocompatibilidade entre os sítios doador e receptor.

Apesar de apresentar características vantajosas quanto ao reparo e cicatrização, a necessidade de um segundo sítio cirúrgico pode significar uma limitação para o procedimento, tendo como desvantagem os riscos e possíveis complicações envolvidas (MAZZONETTO, R. ET AL, 2009). A área doadora eleita pode ser extrabucal, tendo crista ilíaca, calota craniana e tíbia como as mais utilizadas, ou intrabucal, fornecido do ramo mandibular, mento ou túber de maxila. Devido a menor morbidade e possibilidade de ser realizada em nível ambulatorial, a escolha da área intrabucal é mais aceita pelo paciente e mais buscada por profissionais sempre que as necessidades volumétricas e funcionais são compensadas (KLASSMANN, FA ET AL. 2006).

Quando existe uma necessidade de reparo em altura e espessura, a região anterior de mandíbula se sobressai. Pode-se obter do mento o osso cortical, da tábua óssea vestibular, e osso medular (TEIXEIRA, LMS; REHER, P; REHER, VGS, 2008). A facilidade de acesso e proximidade dos sítios doador e receptor favorece a abordagem, além de possibilitar a remoção de um enxerto de incorporação favorável e com baixo potencial de reabsorção, com volume de aproximadamente $5 \mathrm{~mL}$ (MEDONÇA, JCG ET AL, 2015; MAZZONETTO, R. ET AL, 2009).

Para que o implante tenha angulação e profundidade adequada, o enxerto pode ser planejado para que se obtenha um perfil de emergência apropriado e reestabeleça função e estética do paciente (HUPP JR, ELLIS E, TUCKER MR, 2009). Dessa forma, tendo em vista os benefícios da previsibilidade e utilização de enxerto autógenos intrabucais na Implantodontia, o objetivo desse trabalho é apresentar um relato de caso clínico de enxerto autógeno na região anterior de maxila, para posterior instalação e reabilitação com implantes osseointegráveis, utilizando mento como região doadora. 


\section{Considerações éticas}

Os procedimentos empregados neste trabalho seguiram os padrões éticos propostos pela Declaração de Helsinque de 1975, revisada em 2000. A paciente foi tratada na Universidade Federal Fluminense (Niterói/RJ) através da Clínica de Clínica de Extensão em Dentes Inclusos e Cirurgia Oral da Faculdade de Odontologia, com os termos de consentimento livre e esclarecido e de uso de imagens e dados para publicação científica, assinados.

O estudo foi escrito seguindo as Diretrizes do Relatório de Caso Clínico (CARE, www.care-statement.org).

\section{Relato de caso}

Paciente A.R.L.S, leucodema, sexo feminino, 56 anos de idade, procurou a Faculdade de Odontologia da Universidade Federal Fluminense - Clínica de Dentes Inclusos com a necessidade de realização de enxerto para correção de defeito em espessura para posterior reabilitação com implantes osseointegráveis. Ao exame intra oral, constatou-se a presença de ponte fixa sobre dentes com comprometimento dos elementos dentários de suporte. No exame por imagem inicial, verficou-se perda óssea vertical (Fig A1) e de espessura (Fig. B1), impedindo a realização de implantes na região. Para melhorar esse defeito em espessura, planejou-se o enxerto autógeno, sendo escolhido o mento como região doadora. A cirurgia iniciou-se com descolamento da região receptora, próxima a região do elemento 22 (Fig. C1), com incisões apenas intrassulculares, e descorticalização para melhor osseointegração do enxerto (Fig. C2). A região foi protegida com gaze estéril banhada em soro $0,9 \%$ estéril. Em seguida, a região doadora foi incisada, inicialmente com a lâmina de bisturi $\mathrm{n}^{\circ} 15$ angulada em $45^{\circ} \mathrm{em}$ relação ao plano ósseo para incisar mucosa alveolar. A incisão em segundo plano foi realizada com a lâmina angulada em $90^{\circ}$ em relação ao osso, para incisar a musculatura. Após, segue-se com o descolamento até a base da mandíbula (Fig.D1). O enxerto foi inicialmente demarcado com broca carbide 701 até atingir a medular óssea (Fig. D2) e removido com a utilização de cinzel e martelo (Fig. D3), possuindo dimensões aproximadas de $2 \mathrm{~mm}$ de espessura e $10 \mathrm{~mm}$ de comprimento. $\mathrm{O}$ enxerto foi, então, fixado 
ao leito receptor utilizando a técnica compressiva para instalação do parafuso de enxerto $\mathrm{SIN}^{\circledR} 1,6$ x 10mm (Fig C3). Tanto o leito receptor quanto o doador foi preenchido com biomaterial aloplástico Alobone. Por fim, suturou-se a região receptora com pontos do tipo simples e colchoeiro e fio de seda. Já a região doadora necessitou ser suturada, primeiramente, pelo plano muscular com fio reabsorvível e depois o plano mucoso com fio de seda. Após 8 meses do procedimento, contatou-se, através de nova Tomografia Computadorizada (TC), o ganho ósseo em espessura de aproximadamente 5mm (Fig. A2 e Fig. B2), possibilitando a instalação de implantes na região.

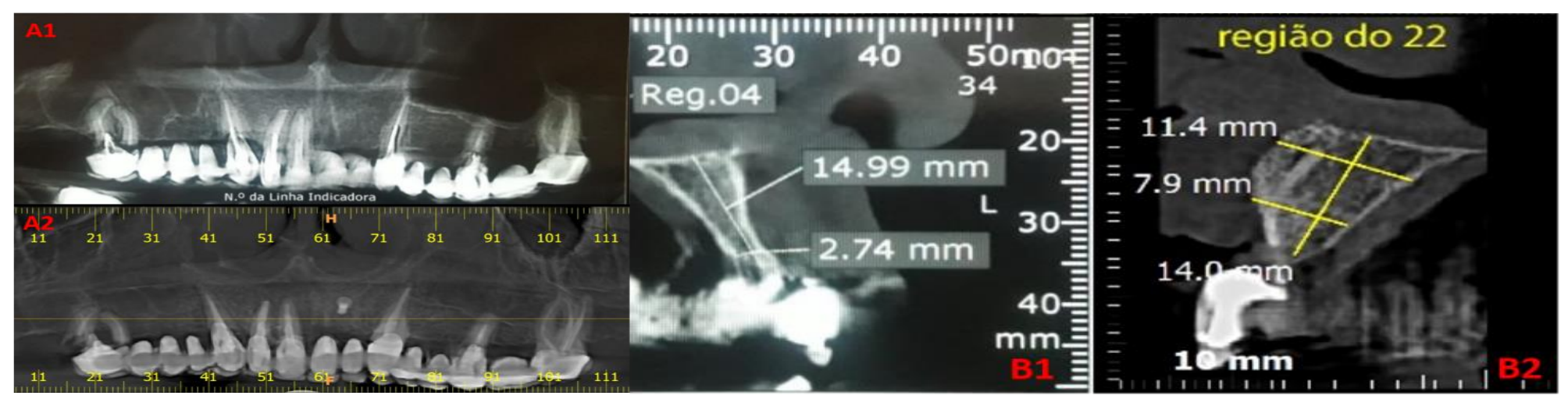

Figura 1. A1) TC inicial; A2) TC realizada após 8 meses do procedimento; B1) Perda de espessura óssea na região do elemento 22, verificada em TC inicial; B2) TC com ganho ósseo de $5 \mathrm{~mm}$ em espessura. 


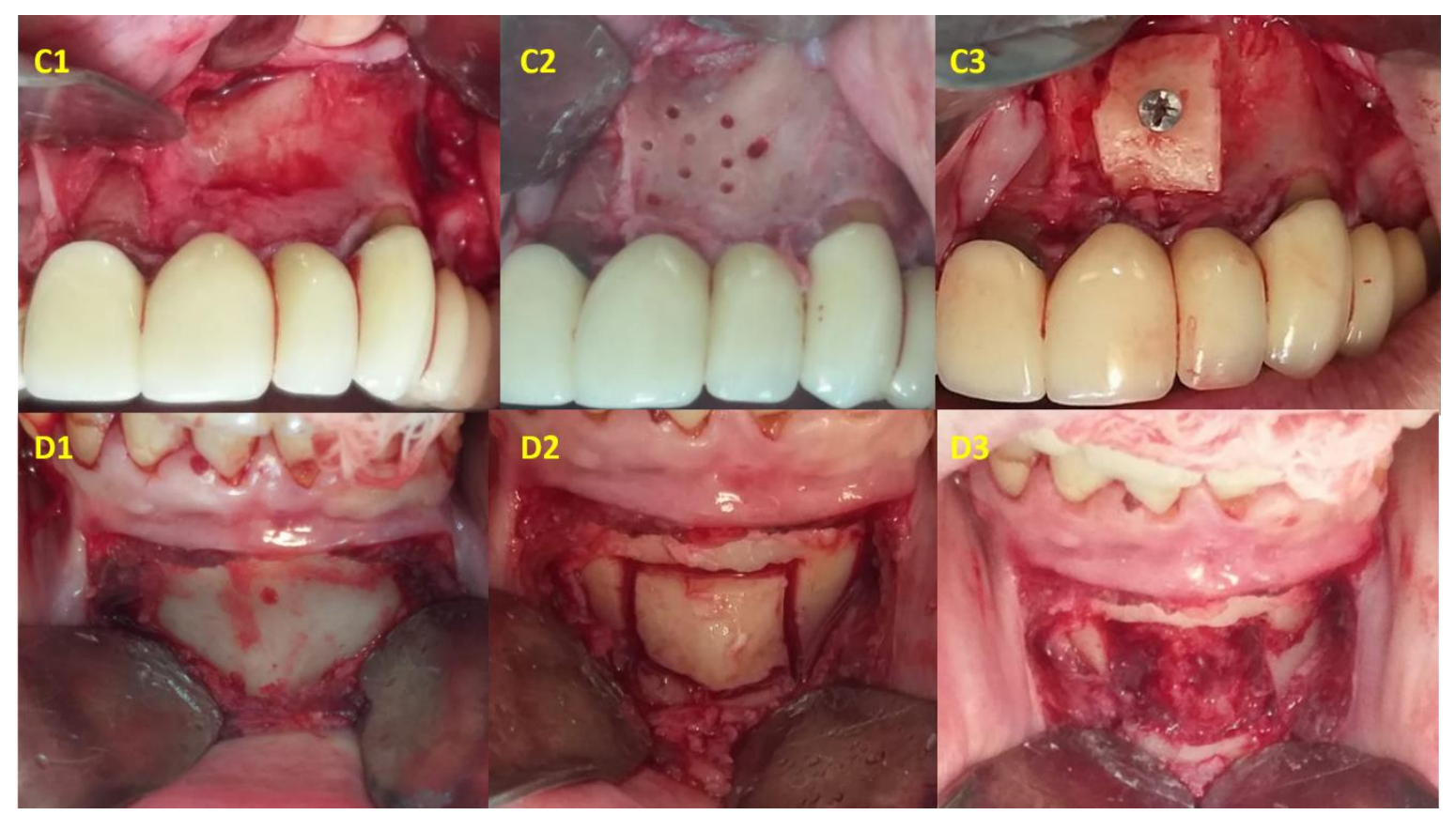

Figura 2. C1) Descolamento mucoperiosteal e exposição da região próxima do elemento 22; C2) Perfurações na tábua óssea para descortilização da região receptora; C3) Enxerto em bloco fixado com parafuso de enxerto $\operatorname{SIN}^{\circledR} 1,6$ x $10 \mathrm{~mm}$ no leito receptor; D1) Descolamento até a base da mandíbula e exposição da região doadora; D2) Demarcação do enxerto com broca esférica; D3) Área doadora após remoção do enxerto com cinzel e martelo. 


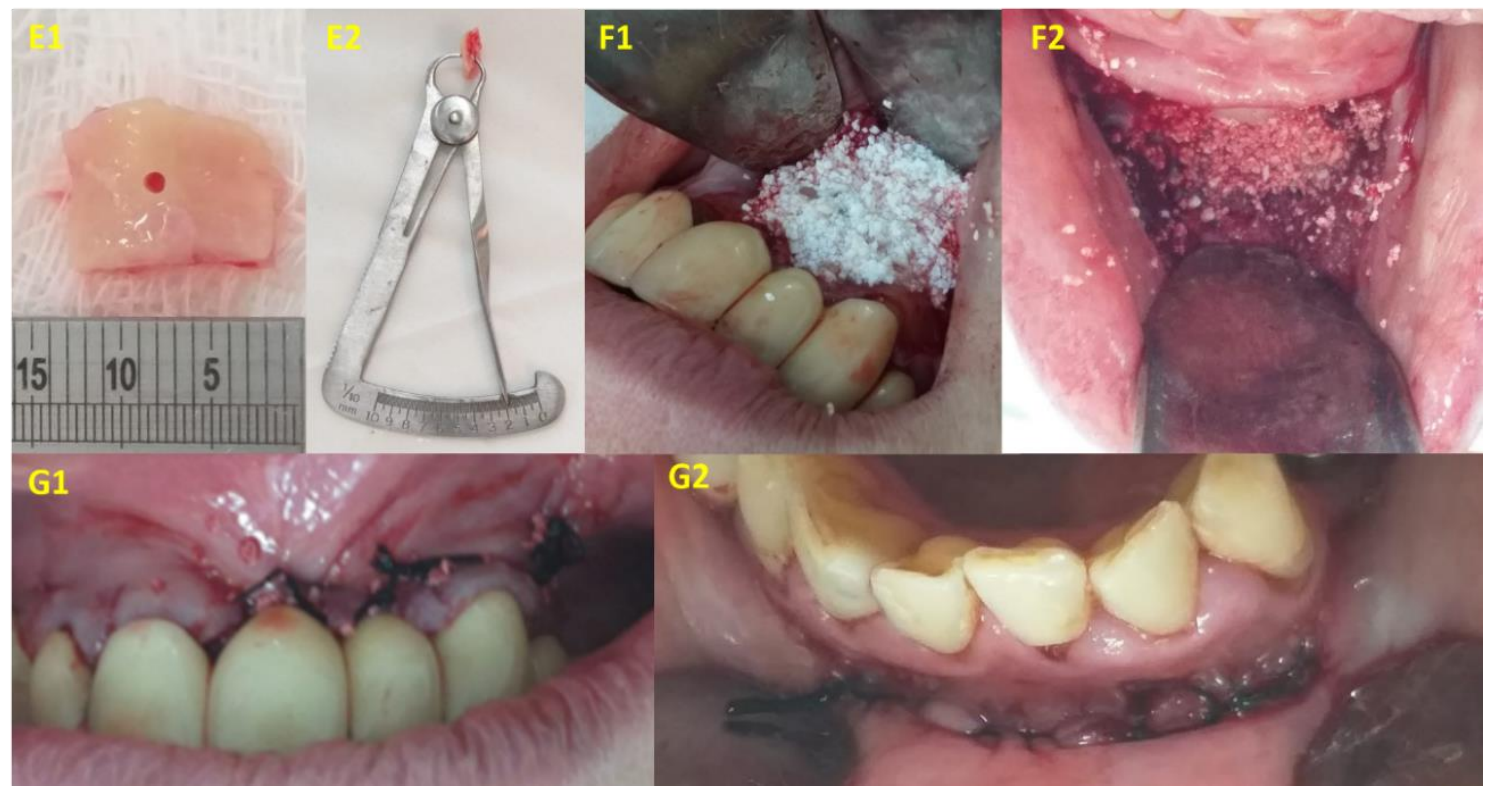

Figura 3. E1) Enxerto em bloco com aproximadamente $10 \mathrm{~mm}$; E2) Enxerto com espessura aproximada de $2 \mathrm{~mm}$; F1) Região receptora preenchida com biomaterial aloplástico Alobone após instalação do enxerto; F2) Região doadora preenchida com material aloplástico Alobone; G1) Pós-operatório imediato da região receptora suturada com pontos do tipo simples e colchoeiro e fio de seda; G2) Pós-operatório imediato da região doadora.

\section{Discussão}

Enxertos ósseos autógenos são amplamente utilizados para reabilitação estética e funcional na Implantodontia. No entanto, a técnica de escolha será direcionada a partir do exame clínico e imaginológico de cada paciente. Além disso, deve-se considerar a condição sistêmica do estado de saúde e local associado ao rebordo adjacente. Após verificada a necessidade de reconstrução e as características do rebordo remanescente, a técnica escolhida apresentou menor morbidade a paciente, sendo capaz de suprir necessidades volumétricas e de biocompatibilidade.

Já estabelecido o diagnóstico do tipo de defeito e o mento como área doadora, a técnica cirúrgica foi determinada pela forma e volume a serem preenchidos. De acordo com a literatura, os enxertos podem ser utilizados em blocos ou particulados. Se for em 
bloco, onlay é frequentemente utilizado para defeitos em espessura ou associados a altura, e inlay para preenchimento alveolar. Quando particulados, necessitam de associação de membrana para recobrir ou de malha de titânio para manutenção do enxerto no rebordo, ou preencher interfaces entre enxerto em bloco (MAZZONETTO, R. ET AL, 2009).

O protocolo para a realização do procedimento deve ser aplicado para ambos os tipos anteriormente citados, devendo realizar o acesso cirúrgico, preparar o leito receptor, remover e armazenar o enxerto mantendo-o hidratado, estabiliza-lo e então recobrir. No presente trabalho, foi realizado o enxerto em bloco retirado do mento, beneficiando da característica costicomedular presente para reparo em espessura do rebordo alveolar, da realização do procedimento em ambiente ambulatorial sob anestesia local.

Contudo, a técnica de enxertia de sínfise tem como principal desvantagem a quantidade limitada de tecido ósseo disponível. Em algumas situações, pode ser necessária a abordagem de mais de uma área doadora. Além disso, apresenta um alto índice de complicações pós-operatórias (MEDONÇA, J.C.G. ET AL, 2015). Para minimizar possíveis intercorrências, os limites de $5 \mathrm{~mm}$ inferiormente à linha mucogengival entre os caninos devem ser respeitados (MAZZONETTO, R. ET AL, 2009).

Uma avaliação retrospectiva de casos de enxerto autógeno associado a implantes de 166 pacientes no período de 1995 a 2014, analisou os fatores predisponentes para insucesso do procedimento. O carregamento precoce, inserção em áreas de baixa qualidade óssea ou caso o leito ósseo receptor não saudável, inviabilizam a osseointegração. Foi observado que $95,17 \%$ dos procedimentos foram bem sucedidos, constatando que o conhecimento do profissional, execução satisfatória da técnica e condições sistêmicas e locais do paciente torna previsível o sucesso do tratamento (SALMEN F.S., ET AL, 2016).

Uma combinação de enxerto autógeno com materiais homógeno, heterógeno ou materiais aloplásticos também pode ser usada para evitar a perda do implante ao amenizar a reabsorção superficial e melhorar o contorno estético, manter o volume e preencher as fenestrações (MAZZONETTO, R. ET AL, 2009). Todavia, dos materiais citados na literatura, o que apresenta as características e mecanismos de ação ideais é o osso autógeno, sendo capaz de promover a odontogênese ao estimular a neoformação óssea a 
partir de células osteoprogenitoras presentes; osteoindução, estimulando a diferenciação de células mesenquimais dos tecidos adjacentes; e osteocondução, fazendo do enxerto o arcabouço para a proliferação das células do hospedeiro (REIS, F.A.R., ET AL, 2019; MAZZONETTO, R. ET AL, 2009).

Como descrito em literaturas da especialidade, a fixação do enxerto deve ser realizada com a utilização de dois parafusos instalados de forma bicortical, para que não ocorra movimentação do enxerto. Porém neste caso clínico, por se tratar de um pequeno enxerto e que se apresentava estável devido as regiões adjacentes ao mesmo: bossa canina e linha média, conseguiu-se boa estabilização do mesmo sem a necessidade da instalação de um segundo parafuso.

Além de sua capacidade osteogênica, o osso autógeno se sobressai por apresentar ausência de hipersensibilidade imunológica, reparação e cicatrização mais rápidas, facilidade de obtenção, menor grau de inflamação, e pelo menor custo, fatores considerados para a execução dos procedimentos realizados no presente trabalho.

\section{Conclusão}

A utilização de enxerto autógeno em bloco mostrou-se um tratamento eficaz por devolver contorno estético do rebordo alveolar, minimizar reabsorção superficial, além de se mostrar como uma alternativa de baixo custo. Após Tomografia Computadorizada de 08 meses do procedimento, verificou que a região enxertada se apresentava pronta para receber o implante e prosseguir com o tratamento reabilitador protético da paciente.

\section{Referências Bibliográficas}

1. MAZZONETTO, R. et al. Reconstruções em implantodontia: protocolos clínicos para o sucesso e previsibilidade. $1^{\text {a }}$ Edição. São Paulo: Editora Napoleão, 2009. 368 p.

2. HUPP, J.R.; ELLIS, E.; TUCKER, M.R. Cirurgia oral e maxilofacial contemporânea.

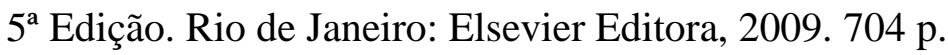


3. TEIXEIRA, L.M.S.; REHER, P.; REHER, V.G.S. Anatomia aplicada à odontologia. $2^{a}$ Edição. Rio de Janeiro: Guanabara Koogan, 2015. 433 p.

4. MEDONÇA, J.C.G. et al. Enxerto ósseo de mento estabilizado em pré-maxila e reabilitação com implantes osseointegrados: relato de caso. Archives of Health Investigation, São Paulo, v. 4, n. 1, p. 13-19, jan. 2015.

5. KLASSMANN, F.A. et al. Enxertos ósseos autógenos de áreas doadoras intra-bucais e procedimentos clínicos integrados possibilitando reabilitação estética e funcional. Rev. Gaúcha de Odontologia, Porto Alegre, v. 54, n. 4, p. 388-392, out./dez. 2006.

6. SALMEN, F.S. et al. Enxerto ósseo para reconstrução óssea alveolar. Revista do Colégio Brasileiro de Cirurgiões, Rio de Janeiro, v.44, n.1, p. 33-40, jan./feb. 2017.

7. REIS, F.A.R. et al. Avaliação das vantagens da realização de enxerto autógeno em prémaxila. Revista Eletrônica Acervo Saúde, v. 20, e.436, fev. 2019. 